\title{
Captured cirrus ice particles in high definition
}

\author{
Nathan Magee $^{1}$, Katie Boaggio ${ }^{2}$, Samantha Staskiewicz ${ }^{3}$, Aaron Lynn ${ }^{1}$, Xuanyi Zhao $^{1}$, Nicholas Tusay ${ }^{1}$, \\ Terance Schuh ${ }^{1}$, Manisha Bandamede ${ }^{4}$, Lucas Bancroft ${ }^{5}$, David Connelly ${ }^{6}$, Kevin Hurler ${ }^{7}$, Bryan Miner ${ }^{1}$, and \\ Elissa Khoudary ${ }^{1}$ \\ ${ }^{1}$ Department of Physics, The College of New Jersey (TCNJ), Ewing, New Jersey, USA \\ ${ }^{2}$ ORISE at US Environmental Protection Agency, Raleigh, North Carolina, USA \\ ${ }^{3}$ Department of Meteorology, The Pennsylvania State University, University Park, Pennsylvania, USA \\ ${ }^{4}$ Ross University School of Medicine, Miramar, Florida, USA \\ ${ }^{5}$ Universal Display Corporation, Ewing, New Jersey, USA \\ ${ }^{6}$ Department of Earth and Atmospheric Sciences, Cornell University, Ithaca, New York, USA \\ ${ }^{7}$ Department of Geological Sciences, University of South Carolina, Columbia, South Carolina, USA
}

Correspondence: Nathan Magee (magee@ $@$ tcnj.edu)

Received: 19 May 2020 - Discussion started: 15 July 2020

Revised: 5 January 2021 - Accepted: 29 January 2021 - Published: 11 May 2021

\begin{abstract}
Cirrus clouds composed of small ice crystals are often the first solid matter encountered by sunlight as it streams into Earth's atmosphere. A broad array of recent research has emphasized that photon particle scattering calculations are very sensitive to ice particle morphology, complexity, and surface roughness. Uncertain variations in these parameters have major implications for successfully parameterizing the radiative ramifications of cirrus clouds in climate models. To date, characterization of the microscale details of cirrus particle morphology has been limited by the particles' inaccessibility and technical difficulty in capturing imagery with sufficient resolution. Results from a new experimental system achieve much higher-resolution images of cirrus ice particles than existing airborne-particle imaging systems. The novel system (Ice Cryo-Encapsulation by Balloon, ICEBall) employs a balloon-borne payload with environmental sensors and hermetically sealed cryo-encapsulation cells. The payload captures ice particles from cirrus clouds, seals them, and returns them via parachute for vapor-locked transfer onto a cryo-scanning electron microscopy stage (cryoSEM). From 2015-2019, the ICE-Ball system has successfully yielded high-resolution particle images on nine cirruspenetrating flights. On several flights, including one highlighted here in detail, thousands of cirrus particles were retrieved and imaged, revealing unanticipated particle morphologies, extensive habit heterogeneity, multiple scales of
\end{abstract}

mesoscopic roughening, a wide array of embedded aerosol particles, and even greater complexity than expected.

\section{Introduction}

Understanding of cirrus cloud microphysics has advanced dramatically in the past several decades thanks to continual technical innovations in satellite remote sensing, in situ aircraft measurements, sophisticated laboratory experiments, and modeling that incorporates this new wealth of data. In combination, the au courant picture of cirrus clouds has emerged: a highly complex system that results in a vast array of cirrus formations, varying in time and location through interdependent mechanisms of microphysics, chemistry, dynamics, and radiation (e.g., Heymsfield et al., 2017). While the net magnitude of cirrus radiative forcing is clearly not as large as thick low-altitude clouds, an intricate picture of climate impacts from cirrus is coming into focus. It now seems clear that both the sign (positive or negative) and strength of cirrus radiative forcings and feedbacks depend on variables that can change with a wide array of parameters: geography; season; time of day; dynamical setting; and the concentrations, shapes, sizes, and textures of the cirrus ice particles themselves (e.g., Burkhardt and Kärcher, 2011; Harrington et al., 2009; Järvinen et al., 2018b, Yi et al., 2016). Furthermore, many of these factors may be changing markedly over 
time as contrail-induced cirrus and changing temperature, humidity, and aerosol in the high troposphere are affected by evolving anthropogenic influences (Randel and Jensen, 2013; Kärcher, 2018; Zhang et al., 2017). Undoubtedly, a sophisticated, high-resolution understanding of cirrus is critical to accurately model the impacts on global and regional climate.

Satellite-derived measurements of cirrus properties have become vastly more sophisticated with the advent of increased spatial and temporal resolution, a broader array of spectral channels, specialized detectors, and advances in scattering theory (e.g., Yang et al., 2008; Baum et al., 2011; Sun et al., 2011; Mauno et al., 2011; Yang et al., 2013; Cole et al., 2014; Tang et al., 2017; Sourdeval et al., 2018; Yang et al., 2018). Where a generation ago it was challenging to even isolate the presence of cirrus clouds in much satellite imagery, it is now routine to derive estimates of ice cloud optical depth, cloud top temperature, cloud top height, and effective particle size and in some cases even to infer the dominant particle habit and roughness of crystal surfaces (McFarlane and Marchand, 2008; King et al., 2013; Cole et al., 2014; Hioki et al., 2016; Saito et al., 2017). The emerging ubiquity of these sophisticated satellite data and highly developed retrieval schemes can sometimes obscure the fact that major fundamental uncertainties remain regarding cirrus microphysical compositions and their intertwined dynamic evolution. In reference to scales of observation and small physical features on ice particles, we refer to several distinct regimes, defined as follows: nanoscale, $1-100 \mathrm{~nm}$; mesoscopic, $100 \mathrm{~nm}-1 \mu \mathrm{m}$; and microscale, $1-500 \mu \mathrm{m}$.

Cloud-particle-imaging probes on research aircraft have also contributed to major leaps in understanding, helping to constrain cirrus property satellite retrievals and climate modeling representations (Baumgarnder et al., 2017; Lawson et al., 2019). These probes deliver particle imaging and concentration measurements that yield unique insights into ice particle habits and distributions in cirrus, though several significant limitations remain. The SPEC Inc. cloud particle imager (CPI) probes have flown for nearly 20 years and can achieve $2.3 \mu \mathrm{m}$ pixel size and $\sim 5 \mu \mathrm{m}$ optical resolutions, and SPEC's 2D-S stereo-imaging probe yields $10 \mu \mathrm{m}$ pixel sizes (Lawson et al., 2019). For example, CPI images of cirrus ice were featured on the June 2001 cover of the Bulletin of the American Meteorological Society (Connelly et al., 2007) and have contributed to many other cloud physics field programs since (for a complete list, see Appendix A in Lawson et al., 2019). Other recent in situ particle measurement innovations include the HOLODEC (Fugal et al., 2004), SID3 (Ulanowski et al., 2012; Järvinen et al., 2018a), and PHIPSHalo (Schnaiter et al., 2018), with imaging resolutions on the order of $5-10 \mu \mathrm{m}$ as well as multi-angle projections and indirect scattering measurements of particle roughness and complexity. High-speed aerodynamics and concerns about instrument-induced crystal shattering have produced some uncertainties regarding inferred particle concentrations, size distributions, and orientations, but perhaps more importantly, the limited optical-resolving power means that in situ imaging instruments are not able to determine fine-scale details of crystal facet roughness or highly complex habit geometry, particularly for small ice crystals. Several groups have also achieved recent in situ measurements of cirrus particles using balloon-borne instruments (Miloshevich and Heymsfield, 1997; Cirisan et al., 2014; Kuhn and Heymsfield, 2016; Wolf et al., 2018). Though this has been a relatively sparse set, some slight momentum appears to be building toward exploiting advantages of this slower-speed probe.

The synthesis that has been emerging describes cirrus clouds that are often but not always dominated by a combination of complex particle morphologies and with crystal facets that usually show high roughening and complexity at the microscale (Baum et al., 2011; Yang et al., 2013; Yi et al., 2013; Tang et al., 2017; Heymsfield et al., 2017; Lawson et al., 2019). Particle complexity has been considered to encompass an array of potential geometric deviations away from a simple hexagonal, single ice crystal: intricate polycrystalline morphological shapes, aggregations of individual particles, partial sublimation of particles, post-sublimation regrowth of microfacets, and inclusions of bubbles and aerosol particles (Ulanowski et al., 2012; Schnaiter et al., 2016; Voigtländer et al., 2018). Even where crystals may present mainly planar facet surfaces, these surfaces are often characterized by regular or irregular patterns of roughening at multiple scales. All aspects of increased complexity and roughening have been shown to smooth and dampen the characteristic peaks in the scattering phase function of hexagonal ice crystals (van Diedenhoven, 2014). The angular integral of the phase function yields the asymmetry parameter, which has been broadly applied as an indicator of net radiative impact of underlying particle microphysics (Baran et al., 2015). With mesoscopic crystal roughness and complexity contributing to less total forward scattering, the asymmetry parameter and net downwelling radiation are reduced (e.g., Yang and Liou, 1998; Um and McFarquhar, 2011; van Diedenhoven et al., 2013). The calculated impacts on cirrus cloud radiative effect are shown to be climatologically significant compared to assumptions that cirrus clouds are composed of less complex crystals (Yang et al., 2013; Järvinen et al., 2018b). Furthermore, beyond questions of particle morphology and radiative balances, major uncertainties around cirrus cloud evolution remain regarding particle nucleation pathways and the interconnected roles of aerosol chemistry, high-altitude humidity, and the subtle dynamics of vertical motion and turbulent eddies in cirrus.

\section{ICE-Ball in situ capture methods}

\subsection{ICE-Ball system}

The Ice Cryo-Encapsulation by Balloon (ICE-Ball) experiment has been designed, refined, and implemented from 
2015-2019. The basic system consists of a $\sim 2 \mathrm{~kg}$ payload ("Crystal Catcher") carried aloft by a $300 \mathrm{~g}$ latex weather balloon. The payload components are enclosed in a mylarwrapped Styrofoam cube (Fig. 1) to prevent electronics from freezing and to comply with Federal Aviation Administration (FAA) regulations for weight, density, and visibility. Figure 1 shows the ICE-Ball system ready to launch, along with a cross-section diagram of the cryo-collection and preservation mechanism. The instrument suite consists of standard balloon sonde sensors (pressure, temperature, and dew point) and also includes HD video (GoPro Session) and dual realtime GPS position tracking (SPOT and GreenAlp). The cryocapture vessel and ice encapsulation cell comprise the novel ice particle capture and preservation mechanism. Several versions of this mechanism have been employed, but in each case, it has consisted of a vacuum-insulated stainless steel vessel ( $250 \mathrm{~mL}$ volume) filled with crushed dry ice and containing a custom-machined sweep tube and ice encapsulation cell. The sweep tube extends slightly above the top of the payload and passively collects particles in its path due to the upward motion of the balloon $(\sim 5 \mathrm{~m} / \mathrm{s})$. When the collection aperture is open, the particles settle to the bottom of the collection tube and are gravitationally deposited in the ice encapsulation cell, which is nestled in the surrounding dry ice. The encapsulation cell interior diameter is $7 \mathrm{~mm}$, and it has an open volume of $0.2 \mathrm{~cm}^{3}$.

During ascent, the balloon is $\sim 5 \mathrm{~m}$ above the payload and does not appear to affect particle concentrations impacting the top of the payload. Several sweep tube geometries and opening sizes have been tested (from 0.5 to $5 \mathrm{~cm}^{2}$ ), but in each case, computational-fluid-dynamics streamline modeling and sample analyses suggest that collection efficiencies are high for particles larger than $50 \mu \mathrm{m}$ diameter and decrease to less than $10 \%$ for particles smaller than $20 \mu \mathrm{m}$ diameter (Supplement file 1). Cirrus cloud conditions and the in-flight collection operation is recorded via the GoPro video. Cirrus particles are routinely observed passing the camera, and $22^{\circ}$ halos and/or circumzenith arcs can often be observed in the video record of each successful flight.

\subsection{Ice crystal preservation}

The apertures to the cryo-vessels' sweep tubes can be opened and closed using a rotational servomotor that is driven by an Arduino microprocessor (a previous version used robotic clamshell seals, as seen in the Supplement video). The Arduino is programmed to open the path to each collection vessel individually at cirrus altitudes that are prescribed before each launch. Immediately after transiting the prescribed collection zone(s), the apertures are closed, and a magnetic sphere is dropped down the collection tube to seal the collected crystals in the small-volume encapsulation cell (see Fig. 1b). This onboard preservation system has been tested to preserve collected crystals in pristine condition for approximately $6 \mathrm{~h}$, which usually provides ample time for recovery.
Upon ICE-Ball landing and recovery, the small-volume encapsulation cell is hermetically double-sealed and stored in dry ice to ensure that crystals are preserved as pristinely as possible. After returning to the lab, the sealed ice crystal samples can also be stored in liquid nitrogen for medium-term storage of up to several days prior to transfer and imaging in the cryo-scanning electron microscopy stage (cryo-SEM).

\subsection{Flight record}

Intensive field campaigns were conducted during June and July of 2016-2019, consisting of 5-10 flights per campaign. In order to proceed with mission launch, the following conditions were required: (1) greater than $50 \%$ projected cirrus coverage at the time of launch; (2) horizontal wind speeds (trajectory mean) less than $30 \mathrm{~m} / \mathrm{s}$; (3) modeled trajectory allowing for a safe launch zone and an open landing zone within a $1 \mathrm{~h}$ drive of The College of New Jersey (TCNJ); (4) FAA approval, requiring flight plan filing $24 \mathrm{~h}$ prior to launch. Conditions that prevented launches on particular days mainly included high wind speeds at altitude and clear skies or poorly predicted cirrus cloud coverage. During mid-Atlantic summer, high-altitude mean wind speeds meet the $30 \mathrm{~m} / \mathrm{s}$ maximum launch threshold approximately $60 \%$ of the time; regional climatological proximity to the jet stream often results in prohibitively high winds in the upper troposphere during other seasons. High wind speeds result in a longer flight trajectory (a typical $25 \mathrm{~m} / \mathrm{s}$ mean wind yields an $\sim 80 \mathrm{~km}$ flight), degrading landing zone accuracy (nominal landing position prediction error radius of $10 \%$ of the trajectory length). Longer flight paths also require additional drive time and increase the risk of landing in an inaccessible or unsafe location (e.g., Atlantic Ocean, military base, airport, or interstate). In the summertime mid-Atlantic region, cirrus coverage is approximately $20 \%$. The accuracy of cirrus coverage forecasts by NCEP weather models was found to be a significant challenge to launch planning. Models of high-cloud forecasts appear not to produce significant skill beyond $\sim 48 \mathrm{~h}$ lead times, though it is likely that these fields have not been refined as carefully as others due to modest influence on surface weather.

It is important to note that this flight planning framework meant that the most successful ice particle collections have occurred in moderately thick synoptic cirrus cloud systems. This is the case for the focal data set in Figs. 2 and 3 and Table 1, and several of the additional data shown in the Supplement file 1 (A and D) also constitute moderately thick frontal cirrus, although none of the sampled cirrus were thick enough to be optically opaque. It is likely that some of these systems have liquid origins, which may be contributing to particle complexity (e.g., Luebke et al., 2016 and Wernli et al., 2016). Several of the Supplement data collections are also from thin, high, or scattered cirrus (Supplement file 1B, E, F, $\mathrm{G}$ ) or convective-origin cirrus (Supplement file 1C). In order to further analyze, quantify, and model the implications 

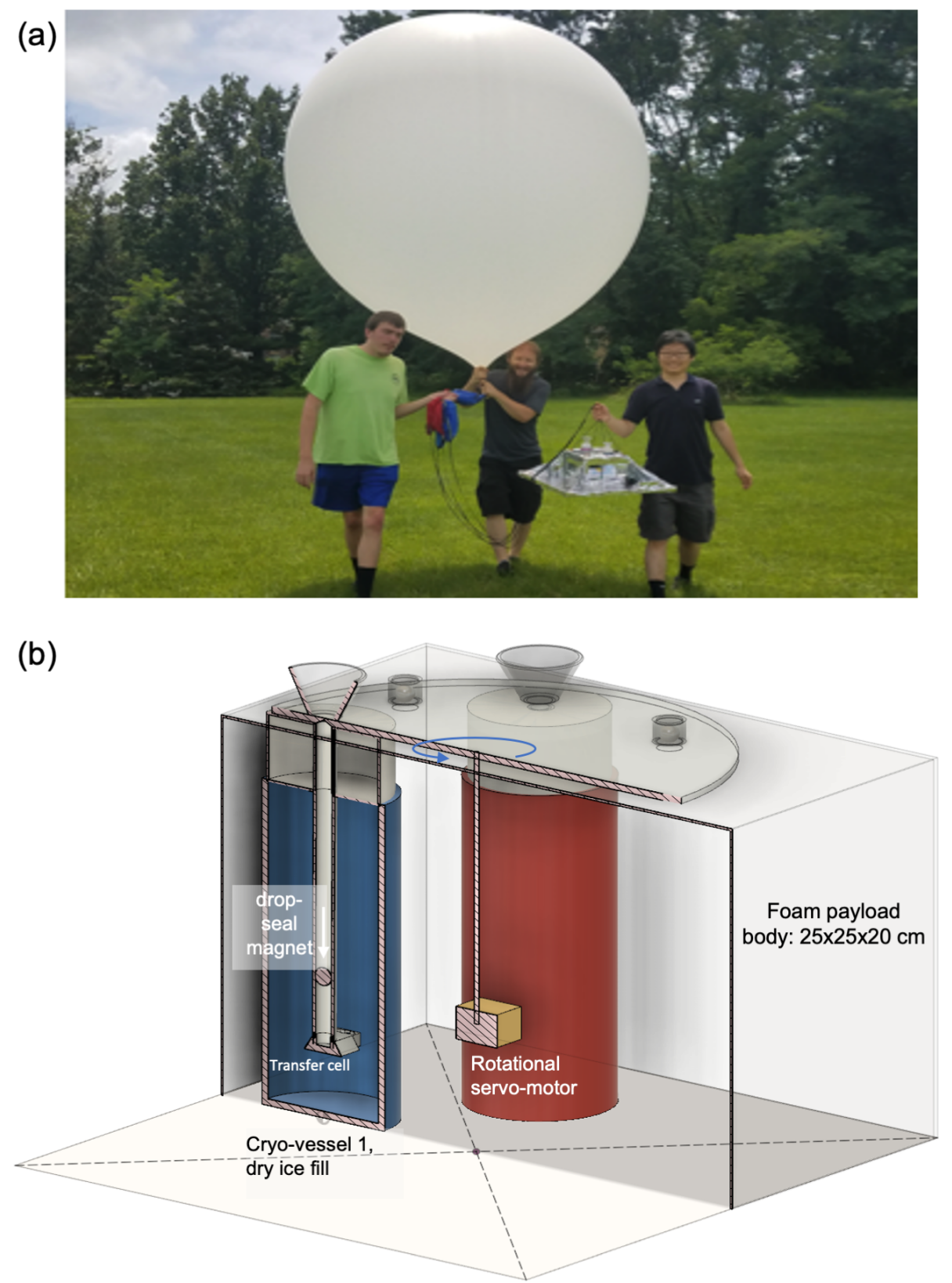

Figure 1. ICE-Ball balloon and payload photo at pre-launch (a) with co-authors Lynn, Tusay, and Zhao (left to right). Diagram of servo-driven sealing of cryo-capture vessels and positioning within the ICE-Ball payload (b).

of ICE-Ball data, it will be essential to target a broad range of cirrus clouds at various heights, thicknesses, growth and dissipation stages, and dynamical origins (Spichtinger and Gierens, 2009).

The novel experimental system has failed to recover ice crystals on more occasions than it succeeded (38\% crystal recovery rate). As the team gained more experience, the success rate improved (65\% during the final campaign), but systemic experimental challenges remain. Conditions that resulted in failure to capture or recover cirrus ice crystals were somewhat varied: system technical failures including prema- ture balloon bursts and frozen electronics (six occurrences), ICE-Ball landing zone (often high in a tree canopy) resulting in recovery time that was too long to preserve crystals (six times), flight trajectory missed scattered cirrus clouds (four times), failure of cryo-transfer or SEM outage (two times). Perhaps the most difficult obstacle to the further development and deployment of the experimental system is the challenge associated with difficult-to-access landing zones. This is especially challenging in the mid-Atlantic, where geography results in only small pockets of public property and high fractions of tree coverage. Remarkably, all 28 flights were 


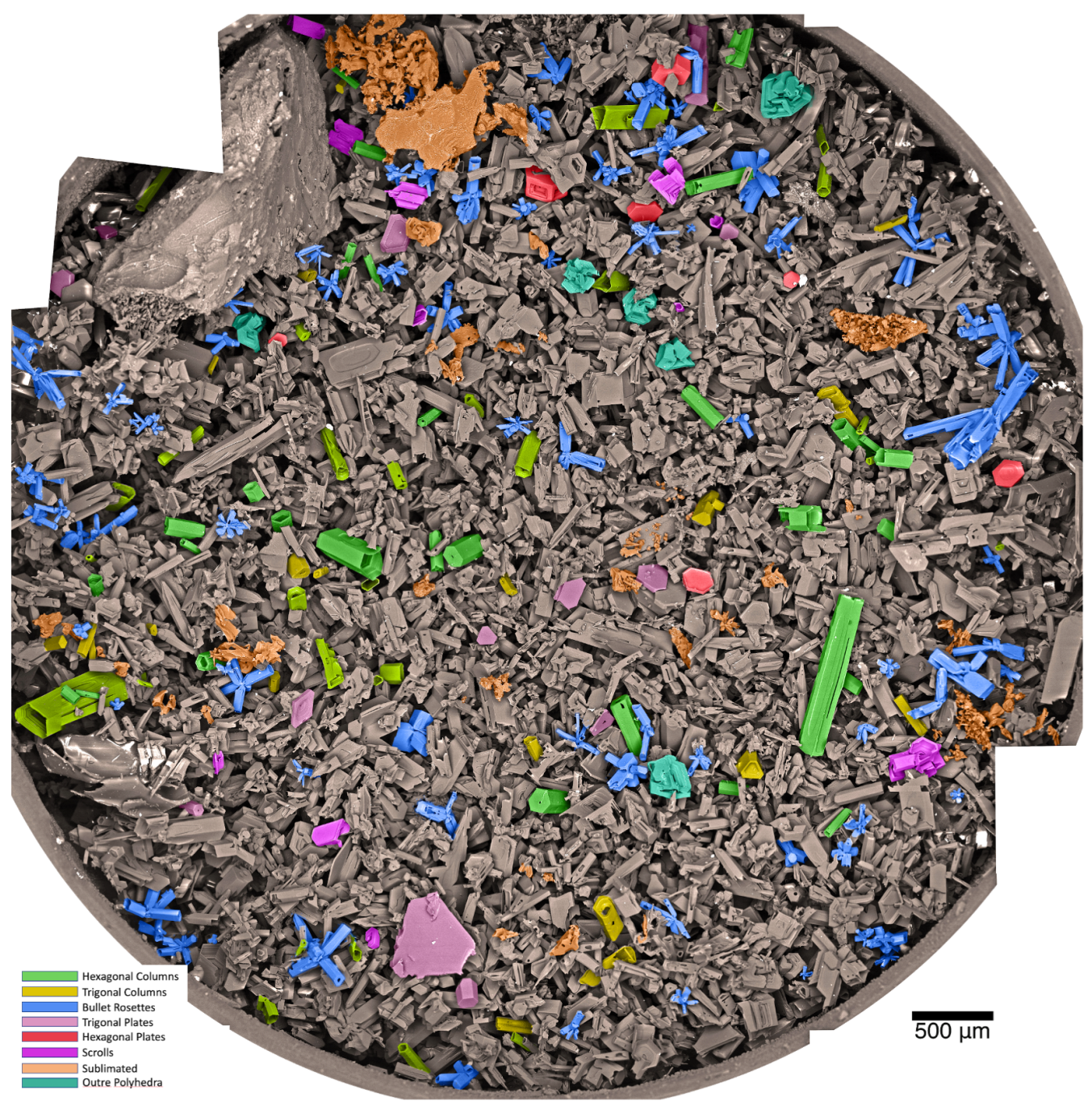

Figure 2. Mosaic of 50 cryo-SEM micrographs of cirrus ice particles captured on 24 April 2018 from $\sim 11 \mathrm{~km}$ altitude at $-50^{\circ} \mathrm{C}$. Each micrograph in this group was acquired at $100 \times$ magnification with a resolution of $\sim 900 \mathrm{~nm}$. The actual large circle diameter is $7 \mathrm{~mm}$. False color shading groups similar crystal habits or highly sublimated particles (orange). Grayscale particles are sharply faceted crystals that do not easily fit in habit classification categories. Table 1 provides class counts and geometric measures.

eventually recovered, but 4 of these included instances of the system caught higher than $15 \mathrm{~m}$ up in a tree, which typically resulted in a complex multi-day effort to retrieve.

\subsection{Vapor-locked transfer and cryo-SEM imaging}

A unique cryo-SEM imaging capability for captured samples is provided by a Hitachi SU5000 SEM, equipped with a Quorum 3010 cryo-system and EDAX Octane energy-dispersive spectroscopy (EDS). The Hitachi SU5000 employs a Schottky field emission electron gun and variable-pressure sample chamber. The combination of the variable-pressure SEM chamber with the Quorum cryo-system is a unique configuration that allows samples to be transferred, held, and imaged uncoated at very low temperature (usually approximately $-160^{\circ} \mathrm{C}$ ) while simultaneously ensuring that excess water vapor is not deposited or removed from the sample surfaces. The Quorum 3010 cryo-system integrates a cryoairlock that transfers a frozen encapsulation cell into the SEM chamber while maintaining cryo-cooling and hermetic sealing throughout the transfer process. Once the SEM chamber has been loaded with the crystal sample and balanced cryo-temperature and pressure achieved, the magnetic seal is removed, and imaging can commence.

Electron beam accelerations of $2-20 \mathrm{kV}$ have been successfully employed with Hitachi backscatter and secondaryelectron detectors to produce micrographs of the captured ice crystals. The backscatter images in particular produce a dramatic contrast between the ice and higher-density embedded aerosol particles that often include silica minerals and metal oxides. The image resolutions of individual micrographs depend on multiple factors including SEM beam energy, spot 

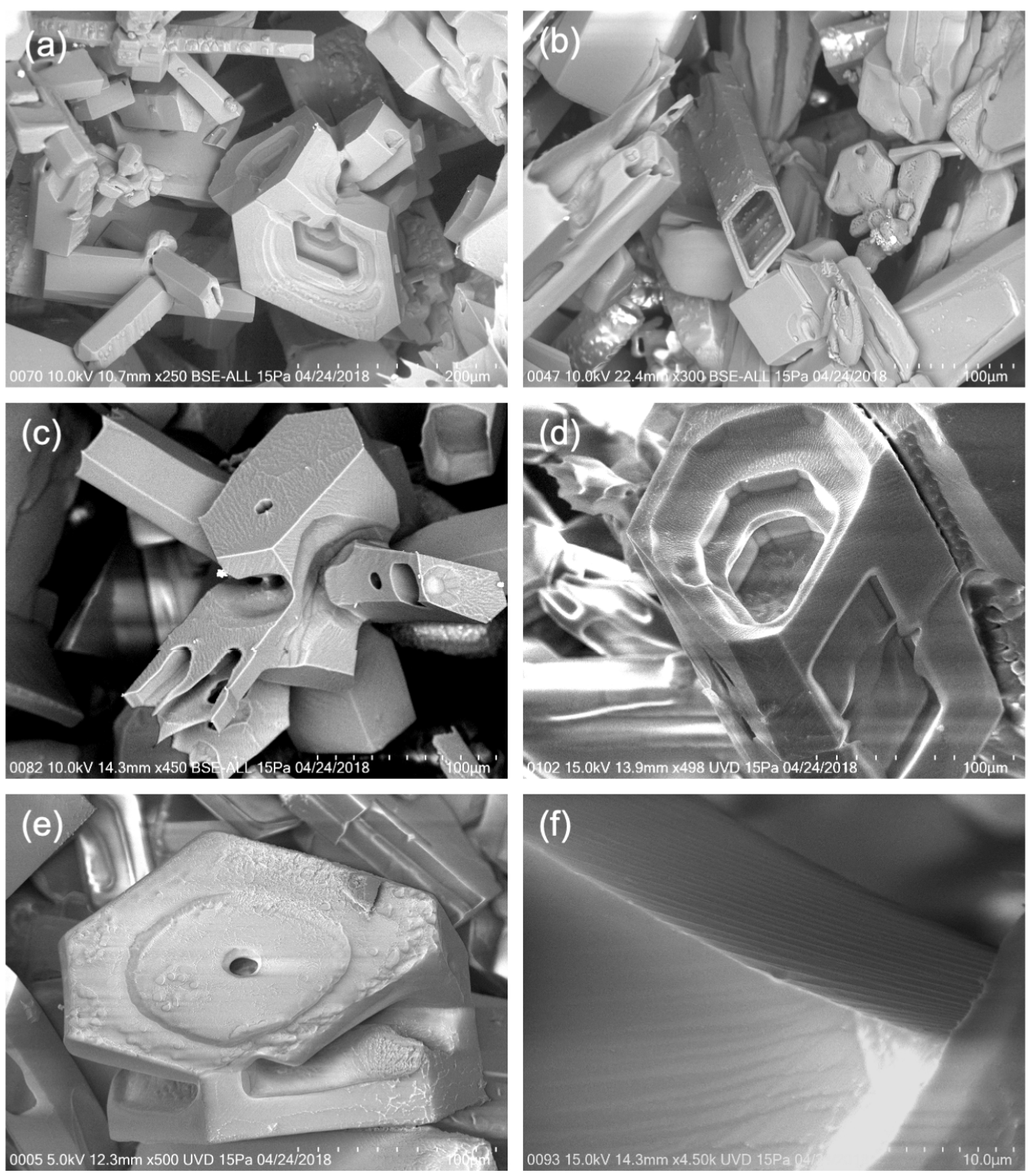

Figure 3. Moderate magnifications $(250 \times$ to $4500 \times)$ of particles, highlighting a wide variety of surface roughening characteristics. (a) Example of a compact-convoluted "outre polyhedron" near several bullet rosettes and non-classified sharp-faceted particles. On close inspection, multiple patterns of roughness are visible, and there are several mineral aerosols (bright white). (b) Rhomboid column with prismatic linear roughening speckled with discrete surface adhesions, possibly from multiple growth cycles. (c) Rosette with mixed-aspect crystals and an array of geometric surface pits and high mesoscopic roughening. (d) Geometrically tiered and hollowed column of irregular basal crosssection with high roughening. (e) Outre polyhedron with central hole and irregular roughening. (f) High magnification of small, uniform angular roughening.

size, working distance, and beam scanning speed. Generally, lower-magnification micrographs near $100 \times$ magnification achieve resolutions of 500-1000 nm, while moderatemagnification images near $2000 \times$ have resolutions of 25 $50 \mathrm{~nm}$. Although used somewhat less frequently for these samples due to limited field of view, higher-magnification images of $5000 \times$ or above routinely achieve $10 \mathrm{~nm}$ resolu- tion. At magnification above $30000 \times$, resolution approaching $2 \mathrm{~nm}$ is possible in this configuration; however, this results in a very small field of view without prominent ice facet features and appears to alter the ice surface unless very low beam energies are used. It is somewhat easier to achieve crisp focus and high-contrast images with resolutions below $5 \mathrm{~nm}$ without deforming the ice surfaces if the 
Table 1. Statistics for particle habit categories in Fig. 2.

\begin{tabular}{|c|c|c|c|c|c|c|c|c|}
\hline $\begin{array}{l}\text { Particle } \\
\text { type }\end{array}$ & $\begin{array}{l}\text { Fig } 1 . \\
\text { color }\end{array}$ & Count & $\begin{array}{r}\text { Fit ellipse } \\
\text { semi-major } \\
\text { mean and } \\
\text { median }(\mu \mathrm{m})\end{array}$ & $\begin{array}{r}\text { Fit ellipse } \\
\text { semi-minor } \\
\text { mean and } \\
\text { median }(\mu \mathrm{m})\end{array}$ & $\begin{array}{r}\text { Cross-section area } \\
\text { mean and } \\
\text { median }\left(\mu \mathrm{m}^{2}\right), \\
\text { total area }(\%)\end{array}$ & $\begin{array}{l}\text { Aspect ratio } \\
\text { mean median }\end{array}$ & $\begin{array}{l}\text { Solidity ratio } \\
\text { mean median }\end{array}$ & Note \\
\hline Columns & $\begin{array}{l}\text { Green } \\
\text { and yellow }\end{array}$ & 83 & $\begin{array}{l}206 \\
167\end{array}$ & $\begin{array}{r}90 \\
105\end{array}$ & $\begin{array}{r}18200 \\
10900 \\
4.0 \%\end{array}$ & $\begin{array}{l}2.39 \\
2.29\end{array}$ & $\begin{array}{l}0.88 \\
0.90\end{array}$ & $\begin{array}{l}\text { Green columns with } \\
\text { hexagonal cross-section, } \\
\text { yellow non-hexagonal; } \\
90 \% \text { show hollowing }\end{array}$ \\
\hline Bullet rosettes & Blue & 81 & $\begin{array}{l}189 \\
101\end{array}$ & $\begin{array}{l}90 \\
57\end{array}$ & $\begin{array}{r}18800 \\
13400 \\
4.0 \%\end{array}$ & $\begin{array}{l}1.84 \\
1.60\end{array}$ & $\begin{array}{l}0.69 \\
0.70\end{array}$ & $\begin{array}{l}\text { Mean of six visible bullets } \\
\text { per rosette; bullets range } \\
\text { from thick to very thin } \\
\text { and solid to hollow }\end{array}$ \\
\hline Highly sublimated & Orange & 62 & $\begin{array}{r}139 \\
93\end{array}$ & $\begin{array}{l}77 \\
50\end{array}$ & $\begin{array}{r}18700 \\
3640 \\
3.1 \%\end{array}$ & $\begin{array}{l}1.86 \\
1.69\end{array}$ & $\begin{array}{l}0.82 \\
0.85\end{array}$ & $\begin{array}{l}\text { Sublimated to extent that } \\
\text { original habit and facet } \\
\text { shapes not distinguishable }\end{array}$ \\
\hline Plates & $\begin{array}{l}\text { Red } \\
\text { and pink }\end{array}$ & 20 & $\begin{array}{l}218 \\
204\end{array}$ & $\begin{array}{l}142 \\
125\end{array}$ & $\begin{array}{r}29300 \\
23800 \\
1.5 \%\end{array}$ & $\begin{array}{l}1.64 \\
1.56\end{array}$ & $\begin{array}{l}0.88 \\
0.91\end{array}$ & $\begin{array}{l}\text { Red plates nearly } \\
\text { hexagonal; pink are } \\
\text { non-hexagonal }\end{array}$ \\
\hline Open scrolls & Purple & 11 & $\begin{array}{l}183 \\
165\end{array}$ & $\begin{array}{r}124 \\
80\end{array}$ & $\begin{array}{r}21100 \\
17900 \\
0.6 \%\end{array}$ & $\begin{array}{l}1.51 \\
1.53\end{array}$ & $\begin{array}{l}0.89 \\
0.89\end{array}$ & $\begin{array}{l}\text { Scroll features overlap } \\
\text { with other habits; } \\
\text { these show dominant scroll } \\
\text { features }\end{array}$ \\
\hline Outre polyhedra & Teal & 6 & $\begin{array}{l}250 \\
230\end{array}$ & $\begin{array}{l}214 \\
193\end{array}$ & $\begin{array}{r}43000 \\
34200 \\
0.7 \%\end{array}$ & $\begin{array}{l}1.17 \\
1.14\end{array}$ & $\begin{array}{l}0.88 \\
0.91\end{array}$ & $\begin{array}{l}\text { Compact particles with } \\
\text { convoluted intersecting } \\
\text { facets }\end{array}$ \\
\hline $\begin{array}{l}\text { Complex } \\
\text { polycrystals and } \\
\text { broken bullets }\end{array}$ & Gray & $\sim 1300$ & $\begin{array}{r}\text { Not } \\
\text { measured }\end{array}$ & $\begin{array}{r}\text { Not } \\
\text { measured }\end{array}$ & $\sim 86 \%$ & $\begin{array}{r}\text { Not } \\
\text { measured }\end{array}$ & $\begin{array}{r}\text { Not } \\
\text { measured }\end{array}$ & $\begin{array}{l}\text { Sharp-faceted polycrystal } \\
\text { particles, often of mixed } \\
\text { aspect ratio, including } \\
\text { broken bullets }(10 \%)\end{array}$ \\
\hline
\end{tabular}

samples are cryo-sputter-coated and then imaged in high vacuum. However, this process has not been used frequently because the cryo-sputtering process appears to obscure the smallest nanoscale surface roughness patterns and also complicates the prospects for using EDS to measure composition of aerosol particles.

\subsection{ICE-Ball upgrades in progress}

Although the ICE-Ball instrument as flown over the past several years has already successfully enabled a new view of cirrus ice particles, several significant modifications to the system are currently in progress. Perhaps most significantly, a high-definition, high-contrast macro-video imaging system will now be integrated into the ICE-Ball payload. This imaging system will be capable of measuring particle concentrations at each point during the cirrus penetrations. A second key upgrade includes the ability to separate captured particles from different regions of a single cirrus layer (e.g., cloud base, cloud middle, cloud top). Together, these improvements will allow better correlation of cloud-scale properties with the cryo-SEM micrographs, promoting the ability to use these measurements for quantitative measures and models of cirrus properties (Sourdeval et al., 2018).

\section{Results: cirrus ice crystal capture}

Particularly with respect to detailed visualization of mesoscopic roughness and complexity, the Ice CryoEncapsulation by Balloon (ICE-Ball) probe demonstrates the capability to dramatically enhance knowledge of fine-scale details of cirrus ice particles. In the four successful collection flights from November 2015-August 2017, small numbers ( $\min 3, \max 20$ ) of intact ice crystals were recovered and imaged by cryo-SEM. In spring 2018, the collection aperture was significantly enlarged, which resulted in collection of thousands of crystals on six successful flights during spring and summer 2018-2019. The flight on 24 April 2018 was particularly successful and provides the focus of the results presented here (Figs. 2 and 3 and Table 1) due to the large number of very-well-preserved crystals and the synchronous alignment with well-defined NASA A-Train satellite measurements.

The other successful recoveries also yielded significant data, including some marked differences in the morphology of ice crystals captured from the high-altitude clouds. Example ice particle images for these additional flights are provided in the Supplement along with a description of the synoptic context. Within this sample set, high, thin in situ cirrus (Fig. 5b and c., Supplement file 1E and G) and ice par- 
ticles within proximity of convection (Supplement file 1C) tended to be smaller and more compact than examples collected from actively growing warm-advection cloud shields (e.g., Figs. 2 and 3, Table 1, and Supplement file 1D). The lone convective-origin ice cloud that was sampled (Supplement file 1C) included several high-resolution images of frozen droplets but did not capture ice particles from a welldeveloped cumulonimbus anvil. Although it may be challenging to get the instrument into an ideal position, future ICE-Ball flight missions will target anvil outflows, aiming to gather high-resolution details of convective-origin ice that have implications in the thunderstorm electrification process (Stith el al., 2016 and Um et al., 2018).

\subsection{Synoptic atmospheric context on 24 April 2018}

On the morning of 24 April 2018, a surface low-pressure system was moving from the Carolinas toward the northeastern United States. Warm advection aloft generated a shield of ascending air to the north and east of the low, resulting in the emergence of a large region of cirrus and cirrostratus. At mid-morning over central New Jersey, this cirrus deck extended from a $9.3 \mathrm{~km}$ base to a $11.5 \mathrm{~km}$ cloud top, with an optical depth between 3-40 (CIRA analysis algorithms on GOES-16 data and MODIS Terra). Satellite images, skew-T diagrams, and back trajectories for this flight context are provided in Supplement file 2. For much of the morning, a faint $22^{\circ}$ optical halo was visible from the ground in the filtered sunlight and is also clearly visible from in-flight video (available in the Supplement). The ICE-Ball system was deployed at 15:05 UTC from near Bordentown, NJ. The payload ascended at approximately $6 \mathrm{~m} / \mathrm{s}$, penetrating the $\sim 2 \mathrm{~km}$ thick cirrostratus near Ewing, NJ at 15:45 UTC. Winds at this altitude were $28 \mathrm{~m} / \mathrm{s}$ from the south, with a cloud base temperature of $-40^{\circ} \mathrm{C}$ and a cloud top temperature of $-55^{\circ} \mathrm{C}$. Video from the flight payload recorded ice particles impacting ICE-Ball for approximately $7 \mathrm{~min}$ as the instrument ascended through the cirrus thickness. While the $22^{\circ}$ halo was clearly evident, no distinct circumzenith arc was visible on this flight, which was often observed in video at altitude on other ICE-Ball cirrus penetrations (for example in the Supplement video: ICE-Ball Flight Montage). The balloon burst at $14 \mathrm{~km}$ altitude, and the payload descended via parachute, landing in Hillsborough, NJ. Recovery occurred approximately $10 \mathrm{~min}$ after landing, and the captured and sealed ice particles were transferred into the cryo-SEM for imaging at approximately 19:00 UTC.

\subsection{Multiform and intricate particle morphology}

Captured ice particles from 24 April 2018 and from other flights show striking morphological diversity and complexity. Particularly in instances where thousands of ice particles were collected from a single cirrostratus (e.g., Fig. 2), it is clear that the imaged particles represent just the topmost sec- tion of the cloud ( $\sim 2 \%$ of $4 \mathrm{~mm}$ deep collection is visible in Fig. 2), with particles collected from the lower and middle parts of the cloud buried below the particles on top. Despite a collection mechanism that principally reveals particles from near the top of a single cirrus layer, an extraordinarily wide variety of habits are apparent from each single cloud penetration, including particles of nearly every cirrus habit classification that is already recognized (e.g., from Bailey and Hallett, 2009) and several other discernible geometric forms that have not been reported elsewhere. Among the most striking features of the particle images is that every aspect of particle morphology is present in multifarious patterns. Even from one section of one cirrus cloud and among recognizable particle habits, major inhomogeneities are present including wide ranges of particle size, aspect ratio, varying degrees of hollowing, trigonal to hexagonal cross-symmetry, broad variations in polycrystallinity, and particles that range from highly sublimated to those with pristinely sharp edges and facets. Perhaps the best way to appreciate this immense diversity in particle form is through the stitched mosaic micrograph from 24 April 2018 (Fig. 2). This mosaic of 50 lower-magnification cryo-SEM images $(100 \times)$ captures the entirety of one ICE-Ball sample collection cryo-cell, with a circular inside diameter of $7.0 \mathrm{~mm}$. Each individual image field is $0.97 \mathrm{~mm}$ tall $\times 1.27 \mathrm{~mm}$ wide, with a pixel resolution of $992 \mathrm{~nm}$. An automated multi-capture algorithm on the Hitachi SEM drove the sample stage to consistent overlap with a high-quality reconstruction; only in the bottom left of the mosaic is some minor mismatch apparent. The mosaic figure uses false color to highlight several particle habits (bullet rosettes, columns, and plates) that fit classic definitions of morphology; particle categories were manually identified and by consensus among three co-authors. In total, these distinct-habit particles number $\sim 185$ of the approximately 1600 individual ice particles that are distinguishable within the depth of focus visible from the top of the sample. The remaining $\sim 88 \%$ of ice particles resolved in Fig. 2 include the following: (a) complex polycrystal assemblages, often not radiating outward from a single point $(\sim 75 \%)$; (b) highly sublimated particles where the original habit is no longer distinct $(\sim 5 \%)$; (c) single bullets apparently broken off from rosettes $(\sim 5 \%)$; and (d) compact particles with convoluted facets $(\sim 1 \%)$. Comparable convoluted crystal forms do not appear to have been reported in the literature, and these particles are labeled as "outre polyhedral". Measurements of cross-section area, ellipse fit dimensions, solidity, and aspect ratio for these particles are provided in Table 1. These measurements are automatically generated by the standard ImageJ-Fiji particle analysis package on the separately false-colored particles in Fig. 2.; solidity is defined as the cross-section area in the plane of view divided by the convexhull particle area enclosure. Bullet rosettes with thin bullets have the lowest solidity (minimum $S=0.44$ ), while compact single crystals have solidity near $S=1$. In this sample, the top focal plane reveals only the first several layers of col- 

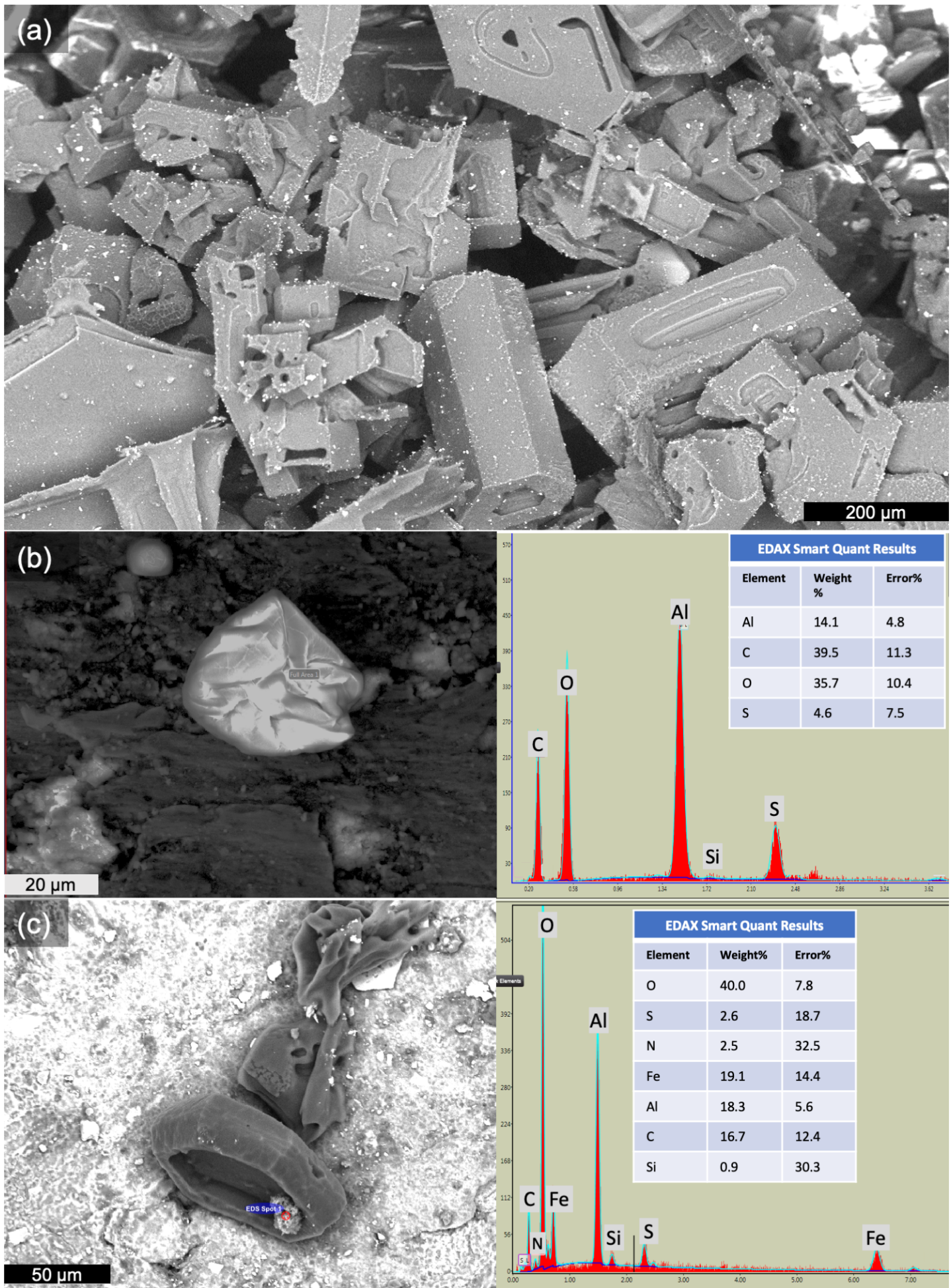

Figure 4. Three-panel particle images and energy-dispersive X-ray spectroscopy (EDAX Octane) statistics on ice particle contaminants. (a) Image of high-aerosol loading on 13 June 2018 at 100× magnification (Supplement file 1D for additional details). (b) Fly ash particle (not ice) captured outside cirrus cloud, with EDS composition. (c) Shallow hollowed trigonal ice particle with iron-rich embedded aerosol (25 June 2019). 

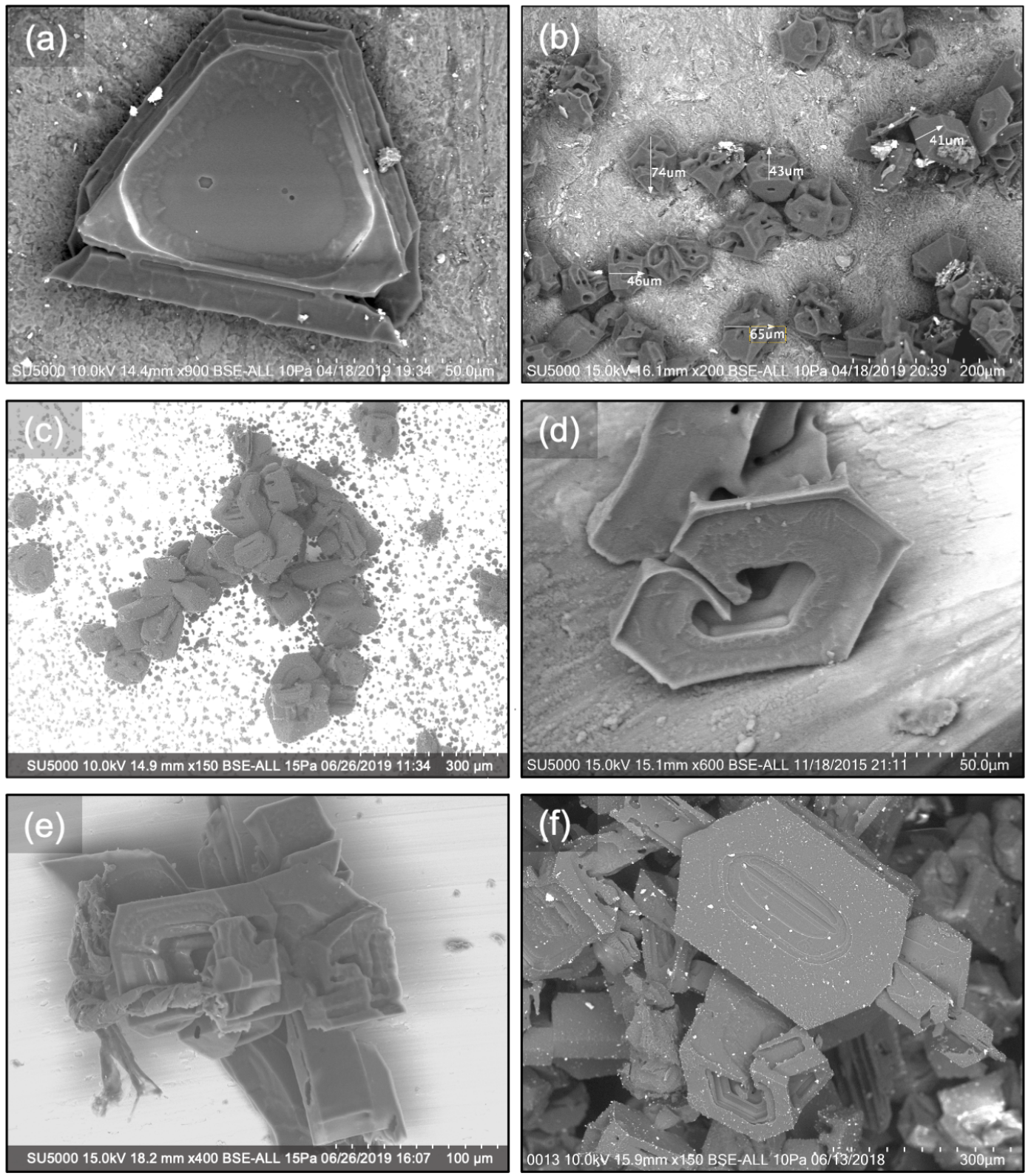

Figure 5. Ice particles with non-classical facet features. (a) Trigonal crystal with three six-sided etch pits, moderate roughening, and aerosol loading. (b) Relatively small, compact ice crystals (mean diameter: $\sim 55 \mu \mathrm{m}$ ) with convoluted hollowing patterns and moderate mineral dust aerosol load. (c) Curving chain of a $\sim 15$-particle aggregate including rosettes, compact crystals, and outre polyhedra. (d) Moderately roughened, scrolled plate with corner fins. (e) Complex rosette with twisted biogenic particle (left side). (f) Flattened, patterned hexagon with many small adhered aerosols and outre polyhedron (below).

lected crystals. The full sample collection was accumulated $4 \mathrm{~mm}$ deep with an estimated $\sim 35$ particles per millimeter of linear packing, and thus an estimated approximately 200000 individual cirrus ice particles were captured and preserved in this sample alone. The large $\sim 2 \mathrm{~mm}$ solid chunk at the top left of Fig. 2 is believed to be a dislodged remnant from the collection-tube machining process; no similar millimeter-sized solid particulate objects have been observed in any other samples.

\subsection{Surface texture roughness with multiple scales and patterning}

Higher-resolution images reveal the topography and textures of crystal facets and edges in greater detail. Even in the most pristinely faceted crystals that show no evidence of sublimation, mesoscopic texture on the facet surfaces is nearly always apparent at some scale. On some particles and facets, the roughening is dramatically apparent, with micrometer- 
scale features in depth and wavelength of the roughening pattern. On other facets, the roughness is significantly more subtle, with dominant patterning at scales less than $200 \mathrm{~nm}$. In addition, some particles show roughness at multiple scales simultaneously. While particle complexity and micrometerscale roughness are apparent at $100 \times$, resolving the smallerscale surface textures requires micrograph resolutions of at least $100 \mathrm{~nm}$ and carefully tuned contrast. Figure 3 highlights varying degrees of surface roughness in six-panel micrographs from 24 April 2018, ranging from $250 \times$ to $20000 \times$ magnification. Panels a and b show examples of the outre polyhedron designation; panel c demonstrates the open scrolling seen on a subset of particle facets. It is straightforward to achieve crisp image focus (from both secondary- and backscatter-electron detectors) from magnifications of $10 \times$ to $5000 \times$ in the Hitachi SU5000 with Quorum cryo-stage operating at $10-20 \mathrm{~Pa}$ in variable-pressure mode with stage temperature near $-160^{\circ} \mathrm{C}$. Beyond $5000 \times$ magnification, crisp focus in variable-pressure mode is harder to achieve, particularly while balancing with a goal of avoiding high beam currents which can induce slight in situ sublimation at higher beam energy, density, and exposure times. Nevertheless, at $-160^{\circ} \mathrm{C}$ and medium beam density, ice particles have extremely low vapor pressure and even smaller vapor pressure gradients such that they can be imaged for hours without noticeable changes in shape or surface texture at the nanometer scale. Particles can even be re-sealed while under cryo-vacuum and removed from the cryo-stage for shortterm storage in low-temperature freezers or liquid nitrogen immersion.

\subsection{Ice-embedded aerosols and particulates}

All ice crystal retrievals (and those that did not capture ice) have also collected numerous aerosol particulates. On flights when no cirrus crystals are captured, the ICE-Ball system nevertheless typically captures several dozen large interstitial aerosols particles ( $>25 \mu \mathrm{m}$ diameter) but very few smaller aerosols $(<25 \mu \mathrm{m}$ diameter). This disparity provides high confidence that the many small aerosol particles observed on ice crystals' surfaces adhered to the surfaces within the cloud and were not separately deposited post-capture. Although it has not yet been tractable to measure a large fraction of these scavenged and embedded particulates, several dozen have been measured by energy-dispersive spectroscopy (EDAX EDS), revealing wide-ranging compositions that include mineral dust, soot, and fly ash and confirming previous reports of biogenic aerosol (e.g., Pratt et al., 2009). Figure 4 includes three examples of aerosols collected by ICE-Ball along with EDS spectra of a fly ash aerosol (Fig. 4b) and iron-rich aerosol particle (Fig. 4c) adhering in the shallow hollow of a trigonal single crystal. The particulates are highly variable in size, concentration, and composition, with particles on the surface of crystals and many additional particles revealed in the residual samples left by a post-imaging sublimation process in the SEM. As the complex ice particles sublimate, the embedded aerosol particulates collapse and coagulate with neighboring particles and leave a cohesive collection of mixed aerosol particulates near the center of the original ice crystal. This evaporative coagulation process may point to a potentially important cloudprocessing effect that could occur during cirrus particle sublimation, possibly enhancing the ice-nucleating efficiency of the original particulates (Mahrt et al., 2019). As aerosols of different origin and chemistry conjoin in close proximity under intense sunlight, the post-sublimation ice particle residuals may serve as an unexpected chemical mixing pot, altering the course of their impact on subsequent cirrus formation. Ice particle residuals have been captured during several previous aircraft field campaigns, but these techniques are primarily restricted to small ice particles (less than $75 \mu \mathrm{m}$ ) and typically cannot provide morphological imaging of aerosol $(\mathrm{Cz}-$ ico and Froyd, 2014). With additional flights and increased sampling statistics, the ICE-Ball aerosol collection technique promises to provide an important complement to research on the origin and processing pathways of particulates in cirrus clouds within the high troposphere and across the tropopause (Zhao et al., 2019).

\section{Conclusions}

Perhaps unsurprisingly, this higher-resolution view of the ice particle constituents of cirrus reveals new and unanticipated complexities compared to existing laboratory, aircraft, and satellite measurements. The measurements from ICE-Ball do not contradict laboratory measurements (Bailey and Hallett, 2004) nor do they really dispute the first-order habit diagrams that encompass cirrus temperatures (Bailey and Hallet, 2009). Many of the recent particle observations based on in situ imaging from aircraft field campaigns and analysis are also largely corroborated (e.g., Fridlind et al., 2016, van Diedenhoven et al., 2016, and Lawson et al., 2019). Nevertheless, present results heighten the appreciation of cirrus particle complexity in four broad themes described below.

\subsection{Immense whole-particle habit heterogeneity within single cirrus clouds}

In all cases where multiple crystals were recovered, we observe that the synoptically forced cirrus clouds contain a multiplicity of recognizable habit types, even within the same region of the cloud and often existing outside of their expected habit temperature and pressure regime. In addition (and in concurrence with Fridlind et al., 2016, and Lawson et al., 2019), we also find that a high fraction of particles could be classified as "irregular" in that they do not fit within an established habit category. The high-resolution images demonstrate that these non-categorized particles are mainly divided between (a) highly sublimated forms where the original habit 
is no longer recognizable and especially (b) sharp-edged, faceted particles with complex polycrystalline morphology that does not neatly fit in established habit categories. In most instances, these polycrystalline assemblages cannot truly be described as bullet or plate rosettes because the multiple crystals often do not radiate outward from a single focus, and they also frequently contain plate-like and columnar crystal forms in a single particle. Furthermore, all of the sharp-edged and neatly faceted crystals with no hint of sublimation commonly occur in direct intermixture with highly sublimated particles. Due to our inherent cloud top sampling bias, this observation may only be particularly apparent at the very upper edges of cirrus clouds, where entrainment mixing may be prevalent and particles also affected by incoming solar radiation. This upper-edge region is of particular radiative importance, especially in optically thicker cirrus, where the dynamics of the upper-cloud supersaturation zone and its uncertain interactions with above-cloud air may play a significant role in governing the life cycle of cirrus (Spichtinger and Gierens, 2009; Wall et al., 2020). Despite this diverse morphology within each single cloud, the set of nine flight samples also reveal significant patterns of particle variations that appear to be linked to the dynamical and air mass characteristics of the cloud. For example, degree of aerosol loading, average particle size, mean aspect ratio, in-cloud particle concentration, and degree of polycrystallinity are fairly consistent within each single collection. On one flight, several sets of collected particles appear as an aggregated chain (Fig. 5c, Supplement file 1G.); this cirrus cloud was not near active convection, but the frontal cirrus original may have derived from modest convection several hours prior to collection.

\subsection{Widespread non-hexagonal faceting, hollowing, and scrolls}

In addition to unexpectedly convoluted whole particles, captured-ice-particle sub-structures and facets also show a sizable fraction of trigonal (e.g., Figs. 4c and 5a), rhomboid (Fig. 3b), and other non-hexagonal symmetries. In fact, facets with hexagonal symmetry appear to be a slight minority. For example, columnar single crystals in Fig. 2 are shaded in yellow for trigonal or other-shaped basal crosssections (53) and green for hexagonal basal cross-sections (30). Bullet rosette cross-sections also appear to follow similar proportions. For both bullet rosettes and columnar habits in Fig. 2, approximately $80 \%$ of crystals demonstrate some degree of hollowing. This proportion is similar, though slightly higher than reported by Schmitt and Heymsfield (2007). Smith et al. (2015) also report experiments on the single-scattering impacts of column hollowing, pointing out that greater hollowing extent tends to increase the asymmetry parameter but that the topographical character of the hollowing itself is also important. In addition to typical center hollowing, a small fraction $(\sim 1 \%)$ of ice particles from multiple flights have prominent "scrolled" geometry (purple in Figs. 2, 5d), which has been reported in lab experiments but rarely observed in the atmosphere. Figure $5 \mathrm{~b}$ shows a set of fairly compact and relatively small crystals; their unusual convoluted faceting would likely not be recognizable without resolutions of $1 \mu \mathrm{m}$ or less. A recent paper by Nelson and Swanson (2019) combines lab growth experiments with adjoining-surface molecular-transport kinetics to explain the development of "protruding growth" features at laterally growing ice facets that may be important contributions to these secondary morphological features. This proposed mechanism also highlights the role of growth and sublimation cycling in these formations and helps to explain the origins of terracing, sheaths, pockets, and trigonal growth, all of which are frequently observed in ICE-Ball samples (Murray et al., 2015).

\subsection{Mesoscopic roughening at multiple scales and diverse texturing}

In high-magnification micrographs with resolution finer than approximately $200 \mathrm{~nm}$, mesoscopic surface roughening on crystal facets and non-faceted sublimation surfaces is nearly always apparent but does not appear to occur at a characteristic scale size or texture pattern in individual clouds or even on a single particle. With the smoothest, flattest facets, roughening patterns may only become apparent with resolutions near or better than $200 \mathrm{~nm}$ combined with carefully tuned contrast. In these instances, the smoothest facets show only subtle topographic variations, with amplitudes smaller than the wavelength of visible light (nano-scale roughening). Many facets show roughness scales (amplitude and pattern wavelength) on the order of $500 \mathrm{~nm}$ (mesoscopic roughening), and yet others reveal more dramatic roughening, with scales in excess of $1 \mu \mathrm{m}$ (microscopic-scale roughening). In our sample retrieval from 24 April 2018, particles in the mesoscopicroughening-scale range appeared most commonly. We observe that these natural cirrus particles typically (but not universally) present linear roughening on prism facets and radial, dendritic, or disordered roughening patterns on basal facets (Fig. 3 and Supplement file 1). These observations of roughening are quite similar to those observed for ice particles grown within environmental SEM (Magee et al., 2014; Pfalzgraff et al., 2010; Neshyba et al., 2013; Butterfield et al., 2017) as well as a new experimental growth chamber built specifically to investigate ice surface roughening (Voigtländer et al., 2018). These observations of roughness at amplitudes and patterning agree with in situ reports of multiscale roughness by Collier et al. (2016). The marked similarities in roughness seen on ICE-Ball samples and lab-grown samples substantiate cryo-SEM and other growth chamber methods as important tools for understanding mesoscopicroughening patterns in cirrus ice growth and sublimation, especially given their unique ability to observe facets dynamically as they experience growth and sublimation cycling. 


\subsection{Composition and morphology of embedded and nucleating aerosol}

Cirrus particles also show high variability with respect to the presence of aerosol particulates adhered to the crystal surfaces and embedded within the sub-surface. In the cleanest cases, most ice particles revealed no obvious $(>50 \mathrm{~nm}$ radius) non-ice aerosols on the surface (e.g., Fig. 3a), while in the dirtiest cases (Fig. 4a, Supplement file 1D), each ice particle averaged several dozen mineral or pollutant aerosols. Biogenic particulates are also seen with some frequency (Fig. 5e). While the presence of diverse, rough, complex crystals was striking in every sample collection, the degree of particulate contamination was highly correlated among individual sample collections, suggesting that air mass effects play a dominant role in widely varying degrees of aerosol loading. The opportunity to directly image aerosol particle morphology, relationship to the ice particle surface, and measurement of composition may help to strengthen understanding of connections between aerosol particles, ice nuclei, ice particle growth, and macro-scale cirrus properties.

Data availability. The data basis for this article is contained in the images from Figs. 2-5 and the three Supplement files. Original fullresolution images can be provided by request to corresponding author Nathan Magee at magee@tcnj.edu.

Supplement. The supplement related to this article is available online at: https://doi.org/10.5194/acp-21-7171-2021-supplement.

Author contributions. NM led ICE-Ball development and deployment. KB and SS made major contributions to system development and data analysis. XZ and EK worked extensively on figures, supplements, and editing. All co-authors participated in multiple fieldcampaign flight operations, particle acquisition, instrument engineering, and cryo-SEM imaging.

Competing interests. The authors declare that they have no conflict of interest.

Acknowledgements. This work was supported by the TCNJ School of Science and Department of Physics. The cryo-SEM facility at TCNJ was made possible by the NJ Building our Future Bond Act. The authors thank TCNJ lab manager Rich Fiorillo for many technical contributions and the Allentown FAA field office for gracious support of balloon launches.

Financial support. This research has been supported by the United States National Science Foundation (grant nos. 1501096 and 1557357).
Review statement. This paper was edited by Martina Krämer and reviewed by two anonymous referees.

\section{References}

Bailey, M. P. and Hallett, J.: Growth Rates and Habits of Ice Crystals between $-20^{\circ}$ and $-70^{\circ} \mathrm{C}$, J. Atmos. Sci., 61, 514-554, 2004.

Bailey, M. P. and Hallett, J.: A comprehensive habit diagram for atmospheric ice crystals: Confirmation from the laboratory, AIRS II, and other field studies, J. Atmos. Sci., 66, 2888-2899, 2009.

Baran, A. J., Furtado, K., Labonnote, L.-C., Havemann, S., Thelen, J.-C., and Marenco, F.: On the relationship between the scattering phase function of cirrus and the atmospheric state, Atmos. Chem. Phys., 15, 1105-1127, https://doi.org/10.5194/acp15-1105-2015, 2015.

Baum, B. A., Yang, P., Heymsfield, A. J., Schmitt, C. G., Xie, Y., Bansemer, A., Hu, Y. J., and Zhang, Z: Improvements in Shortwave Scattering and Absorption Models for the Remote Sensing of Ice Clouds, J. Appl. Meteor. Climatol., 50, 1037-1056, 2011.

Baumgardner, D., Abel, S. J., Axisa, D., Cotton, R., Crosier, J., Field, P., Gurganus, C., Heymsfield, A., Korolev, A., Kraemer, M., and Lawson, P.: Cloud ice properties: In situ measurement challenges, Ice Formation and Evolution in Clouds and Precipitation: Measurement and Modeling Challenges, Meteor. Monogr., 58, 9.1-9.23, https://doi.org/10.1175/AMSMONOGRAPHS-D16-0011.1, 2017.

Burkhardt, U. and Kärcher, B.: Global radiative forcing from contrail cirrus, Nat. Clim. Change, 1, 54-58, 2011.

Butterfield, N., Rowe, P. M., Stewart, E., Roesel, D., and Neshyba, S.: Quantitative three-dimensional ice roughness from scanning electron microscopy, J. Geophys. Res.-Atmos., 122, 3023-3041, 2017.

Cirisan, A., Luo, B. P., Engel, I., Wienhold, F. G., Sprenger, M., Krieger, U. K., Weers, U., Romanens, G., Levrat, G., Jeannet, P., Ruffieux, D., Philipona, R., Calpini, B., Spichtinger, P., and Peter, T.: Balloon-borne match measurements of midlatitude cirrus clouds, Atmos. Chem. Phys., 14, 7341-7365, https://doi.org/10.5194/acp-14-7341-2014, 2014.

Cole, B. H., Yang, P., Baum, B. A., Riedi, J., and C.-Labonnote, L.: Ice particle habit and surface roughness derived from PARASOL polarization measurements, Atmos. Chem. Phys., 14, 3739 3750, https://doi.org/10.5194/acp-14-3739-2014, 2014.

Collier, C. T., Hesse, E., Taylor, L., Ulanowski, Z., Penttilä, A., and Nousiainen, T.: Effects of surface roughness with two scales on light scattering by hexagonal ice crystals large compared to the wavelength: DDA results, J. Quant. Sprectrosc. Ra., 182, 225239, 2016.

Connolly, P., Flynn, M., Ulanowski, Z., Chourlatan, T. W., Gallagher, M., and Bower, K. N.: Calibration of the Cloud Particle Imager Probes Using Calibration Beads and Ice Crystal Analogs: The Depth of Field, J. Atmos. Ocean. Tech., 24, 1860-1879, 2007.

Cziczo, D. J. and Froyd, K. D.: Sampling the composition of cirrus ice residuals, Atmos. Res., 142, 15-31, 2014.

Fridlind, A. M., Atlas, R., van Diedenhoven, B., Um, J., McFarquhar, G. M., Ackerman, A. S., Moyer, E. J., and Lawson, R. P.: Derivation of physical and optical properties of mid-latitude cirrus ice crystals for a size-resolved cloud microphysics model, At- 
mos. Chem. Phys., 16, 7251-7283, https://doi.org/10.5194/acp16-7251-2016, 2016.

Fugal, J. P., Shaw, R. A., Saw, E. W., and Sergeyev, A. V... Airborne digital holographic system for cloud particle measurements, Appl. Optics, 43, 5987-5995, 2004.

Harrington, J. Y., Lamb, D., and Carver, R.: Parameterization of surface kinetic effects for bulk microphysical models: Influences on simulated cirrus dynamics and structure, J. Geophys. Res., 114, D06212, https://doi.org/10.1029/2008JD011050, 2009.

Heymsfield, A. J., Krämer, M., Luebke, A., Brown, P., Cziczo, D. J., Franklin, C., Lawson, P., Lohmann, U., McFarquhar, G., Ulanowski, Z., and Van Tricht, K.: Cirrus clouds, Meteorol. Monogr., 58, 2.1-2.26, https://doi.org/10.1175/AMSMONOGRAPHS-D-16-0010.1, 2017.

Hioki, S., Yang, P., Baum, B. A., Platnick, S., Meyer, K. G., King, M. D., and Riedi, J.: Degree of ice particle surface roughness inferred from polarimetric observations, Atmos. Chem. Phys., 16, 7545-7558, https://doi.org/10.5194/acp-16-7545-2016, 2016.

Järvinen, E., Wernli, H., and Schnaiter, M.: Investigations of Mesoscopic Complexity of Small Ice Crystals in Midlatitude Cirrus, Geophys. Res. Let., 45, 11-465, 2018a.

Järvinen, E., Jourdan, O., Neubauer, D., Yao, B., Liu, C., Andreae, M. O., Lohmann, U., Wendisch, M., McFarquhar, G. M., Leisner, T., and Schnaiter, M.: Additional global climate cooling by clouds due to ice crystal complexity, Atmos. Chem. Phys., 18, 15767-15781, https://doi.org/10.5194/acp-18-157672018, 2018b.

Kärcher, B.: Formation and radiative forcing of contrail cirrus, Nat. Commun., 9, 1824, https://doi.org/10.1038/s41467-018-04068$0,2018$.

King, N. J., Bower, K. N., Crosier, J., and Crawford, I.: Evaluating MODIS cloud retrievals with in situ observations from VOCALS-REx, Atmos. Chem. Phys., 13, 191-209, https://doi.org/10.5194/acp-13-191-2013, 2013.

Kuhn, T. and Heymsfield, A. J.: In situ balloon-borne ice particle imaging in high-latitude cirrus, Pure Appl. Geophys., 173, 30653084, 2016.

Lawson, R. P., Woods, S., Jensen, E., Erfani, E., Gurganus, C., Gallagher, M., Connolly, P., Whiteway, J., Baran, A. J., May, P., and Heymsfield, A.: Review of ice particle shapes in cirrus formed in situ and in anvils, J. Geophys. Res.-Atmos., 124, 10049-10090, 2019.

Luebke, A. E., Afchine, A., Costa, A., Grooß, J.-U., Meyer, J., Rolf, C., Spelten, N., Avallone, L. M., Baumgardner, D., and Krämer, M.: The origin of midlatitude ice clouds and the resulting influence on their microphysical properties, Atmos. Chem. Phys., 16, 5793-5809, https://doi.org/10.5194/acp-16-5793-2016, 2016.

Magee, N. B., Miller, A., Amaral, M., and Cumiskey, A.: Mesoscopic surface roughness of ice crystals pervasive across a wide range of ice crystal conditions, Atmos. Chem. Phys., 14, 1235712371, https://doi.org/10.5194/acp-14-12357-2014, 2014.

Mahrt, F., Kilchhofer, K., Marcolli, C., Grönquist, P., David, R. O., Rösch, M., Lohmann, U., and Kanji, Z. A.: The Impact of Cloud Processing on the Ice Nucleation Abilities of Soot Particles at Cirrus Temperatures, J. Geophys. Res.-Atmos., 125, e2019JD030922, https://doi.org/10.1029/2019JD030922, 2019.

Mauno, P., McFarquhar, G. M., Räisänen, P., Kahnert, M., Timlin, M. S., and Nousiainen, T.: The influence of observed cirrus microphysical properties on shortwave radiation: A case study over Oklahoma, J. Geophys. Res., 116, D22208, https://doi.org/10.1029/2011JD016058, 2011.

McFarlane, S. A. and Marchand, R. T.: Analysis of ice crystal habits derived from MISR and MODIS observations over the ARM Southern Great Plains site, J. Geophys. Res.-Atmos., 113, D07209, https://doi.org/10.1029/2007JD009191, 2008.

Miloshevich, L. M. and Heymsfield, A. J.: A balloon-borne continuous cloud particle replicator for measuring vertical profiles of cloud microphysical properties: Instrument design, performance, and collection efficiency analysis, J. Atmos. Ocean. Tech., 14, 753-768, 1997.

Murray, B. J., Salzmann, C. G., Heymsfield, A. J., Dobbie, S., Neely III, R. R., and Cox, C. J.: Trigonal ice crystals in Earth's atmosphere, B. Am. Meteorol. Soc., 96, 1519-1531, 2015.

Nelson, J. and Swanson, B. D.: Lateral facet growth of ice and snow - Part 1: Observations and applications to secondary habits, Atmos. Chem. Phys., 19, 15285-15320, https://doi.org/10.5194/acp-19-15285-2019, 2019.

Neshyba, S. P., Lowen, B., Benning, M., Lawson, A., and Rowe, P. M.: Roughness metrics of prismatic facets of ice, J. Geophys. Res.-Atmos., 118, 3309-3318, https://doi.org/10.1002/jgrd.50357, 2013.

Pfalzgraff, W. C., Hulscher, R. M., and Neshyba, S. P.: Scanning electron microscopy and molecular dynamics of surfaces of growing and ablating hexagonal ice crystals, Atmos. Chem. Phys., 10, 2927-2935, https://doi.org/10.5194/acp-102927-2010, 2010.

Pratt, K. A., DeMott, P. J., French, J. R., Wang, Z., Westphal, D. L., Heymsfield, A. J., and Prather, K. A.: In situ detection of biological particles in cloud ice-crystals, Nat. Geosci., 2, 398, https://doi.org/10.1038/NGEO521, 2009.

Randel, W. J. and Jensen, E. J.: Physical processes in the tropical tropopause layer and their roles in a changing climate, Nat. Geosci., 6, 169, https://doi.org/10.1038/NGEO1733, 2013.

Saito, M., Iwabuchi, H., Yang, P., Tang, G., King, M. D., and Sekiguchi, M.: Ice particle morphology and microphysical properties of cirrus clouds inferred from combined CALIOP-IIR measurements, J. Geophys. Res., 122, 4440-4462, 2017.

Schmitt, C. G. and Heymsfield, A. J.: On the occurrence of hollow bullet rosette- and column-shaped ice crystals in midlatitude cirrus, J. Atmos. Sci., 64, 4514-4519, 2007.

Schnaiter, M., Järvinen, E., Vochezer, P., Abdelmonem, A., Wagner, R., Jourdan, O., Mioche, G., Shcherbakov, V. N., Schmitt, C. G., Tricoli, U., Ulanowski, Z., and Heymsfield, A. J.: Cloud chamber experiments on the origin of ice crystal complexity in cirrus clouds, Atmos. Chem. Phys., 16, 5091-5110, https://doi.org/10.5194/acp-16-5091-2016, 2016.

Schnaiter, M., Järvinen, E., Abdelmonem, A., and Leisner, T.: PHIPS-HALO: the airborne particle habit imaging and polar scattering probe - Part 2: Characterization and first results, Atmos. Meas. Tech., 11, 341-357, https://doi.org/10.5194/amt-11341-2018, 2018.

Smith, H. R., Connolly, P. J., Baran, A. J., Hesse, E., Smedley, A. R., and Webb, A. R.: Cloud chamber laboratory investigations into scattering properties of hollow ice particles, J. Quant. Sprectrosc. Ra., 157, 106-118, 2015.

Sourdeval, O., Gryspeerdt, E., Krämer, M., Goren, T., Delanoë, J., Afchine, A., Hemmer, F., and Quaas, J.: Ice crystal number con- 
centration estimates from lidar-radar satellite remote sensing Part 1: Method and evaluation, Atmos. Chem. Phys., 18, 1432714350, https://doi.org/10.5194/acp-18-14327-2018, 2018.

Spichtinger, P. and Gierens, K. M.: Modelling of cirrus clouds - Part 1b: Structuring cirrus clouds by dynamics, Atmos. Chem. Phys., 9, 707-719, https://doi.org/10.5194/acp-9-707-2009, 2009.

Stith, J. L., Basarab, B., Rutledge, S. A., and Weinheimer, A.: Anvil microphysical signatures associated with lightningproduced $\mathrm{NO}_{x}$, Atmos. Chem. Phys., 16, 2243-2254, https://doi.org/10.5194/acp-16-2243-2016, 2016.

Sun, W., Hu, Y., Lin, B., Liu, Z., and Videen, G.: The impact of ice cloud particle microphysics on the uncertainty of ice water content retrievals, J. Quant. Sprectrosc. Ra., 112, 189-196, 2011.

Tang, G., Panetta, R. L., Yang, P., Kattawar, G. W., and Zhai, P. W.: Effects of ice crystal surface roughness and air bubble inclusions on cirrus cloud radiative properties from remote sensing perspective, J. Quant. Sprectrosc. Ra., 195, 119-131, 2017.

Ulanowski, Z., Hirst, E., Kaye, P. H., and Greenaway, R.: Retrieving the size of particles with rough and complex surfaces from twodimensional scattering patterns, J. Quant. Sprectrosc. Ra., 113, 2457-2464, 2012.

Um, J. and McFarquhar, G. M.: Dependence of the single-scattering properties of small ice crystals on idealized shape models, Atmos. Chem. Phys., 11, 3159-3171, https://doi.org/10.5194/acp11-3159-2011, 2011.

Um, J., McFarquhar, G. M., Stith, J. L., Jung, C. H., Lee, S. S., Lee, J. Y., Shin, Y., Lee, Y. G., Yang, Y. I., Yum, S. S., Kim, B.G., Cha, J. W., and Ko, A.-R.: Microphysical characteristics of frozen droplet aggregates from deep convective clouds, Atmos. Chem. Phys., 18, 16915-16930, https://doi.org/10.5194/acp-1816915-2018, 2018.

van Diedenhoven, B.: The prevalence of the 22 halo in cirrus clouds, J. Quant. Sprectrosc. Ra., 146, 475-479, 2014.

van Diedenhoven, B., Cairns, B., Fridlind, A. M., Ackerman, A. S., and Garrett, T. J.: Remote sensing of ice crystal asymmetry parameter using multi-directional polarization measurements Part 2: Application to the Research Scanning Polarimeter, Atmos. Chem. Phys., 13, 3185-3203, https://doi.org/10.5194/acp13-3185-2013, 2013.

van Diedenhoven, B., Ackerman, A. S., Fridlind, A. M., and Cairns, B.: On averaging aspect ratios and distortion parameters over ice crystal population ensembles for estimating effective scattering asymmetry parameters, J. Atmos. Sci., 73, 775-787, 2016.

Voigtländer, J., Chou, C., Bieligk, H., Clauss, T., Hartmann, S., Herenz, P., Niedermeier, D., Ritter, G., Stratmann, F., and Ulanowski, Z.: Surface roughness during depositional growth and sublimation of ice crystals, Atmos. Chem. Phys., 18, 1368713702, https://doi.org/10.5194/acp-18-13687-2018, 2018.
Wall, C. J., Norris, J. R., Gasparini, B., Smith Jr., W. L., Thieman, M. M., and Sourdeval, O.: Observational Evidence that Radiative Heating Modifies the Life Cycle of Tropical Anvil Clouds, J. Climate, 33, 8621-8640, 2020.

Wernli, H., Boettcher, M., Joos, H., Miltenberger, A. K., and Spichtinger, P.: A trajectory-based classification of ERA-Interim ice clouds in the region of the North Atlantic storm track, Geophys. Res. Lett., 43, 6657-6664, 2016.

Wolf, V., Kuhn, T., Milz, M., Voelger, P., Krämer, M., and Rolf, C.: Arctic ice clouds over northern Sweden: microphysical properties studied with the Balloon-borne Ice Cloud particle Imager B-ICI, Atmos. Chem. Phys., 18, 17371-17386, https://doi.org/10.5194/acp-18-17371-2018, 2018.

Yang, P. and Liou, K. N.: Single-Scattering Properties of Complex Ice Crystals in Terrestrial Atmosphere, Contr. Atmos. Phys., 71, 223-248, 1998.

Yang, P., Hong, G., Kattawar, G., Minnis, P., and Hu, Y.: Uncertainties Associated With the Surface Texture of Ice Particles in Satellite-Based Retrieval of Cirrus Clouds: Part II-Effect of Particle Surface Roughness on Retrieved Cloud Optical Thickness and Effective Particle Size, IEEE T. Geosci. Remote, 46, 19481957, 2008.

Yang, P., Bi, L., Baum, B. A., Liou, K. N., Kattawar, G. W., Mishchenko, M. I., and Cole, B.: Spectrally Consistent Scattering, Absorption, and Polarization Properties of Atmospheric Ice Crystals at Wavelengths from 0.2 to $100 \mu \mathrm{m}$, J. Atmos. Sci., 70, 330-347, 2013.

Yang, P., Hioki, S., Saito, M., Kuo, C.-P., Baum, B. A., and Liou, K. N.: A review of ice cloud optical property models for passive satellite remote sensing, Atmosphere, 9, 499, https://doi.org/10.3390/atmos9120499, 2018.

Yi, B., Yang, P., Baum, B. A., L'Ecuyer, T., Oreopoulos, L., Mlawer, E. J., Heymsfield, A. J., and Liou, K. N.: Influence of ice particle surface roughening on the global cloud radiative effect, J. Atmos. Sci., 70, 2794-2807, https://doi.org/10.1175/JAS-D-13020.1, 2013.

Yi, B., Yang, P., Liu, Q., Delst, P., Boukabara, S. A., and Weng, F.: Improvements on the ice cloud modeling capabilities of the Community Radiative Transfer Model, J. Geophys. Res.-Atmos., 121, 13577-13590, https://doi.org/10.1002/2016JD025207, 2016.

Zhang, Y., Forrister, H., Liu, J., Dibb, J., Anderson, B., Schwarz, J. P., and Nenes, A.: Top-of-atmosphere radiative forcing affected by brown carbon in the upper troposphere, Nat. Geosci., 10, 486489, https://doi.org/10.1038/NGEO2960, 2017.

Zhao, B., Wang, Y., Gu, Y., Liou, K. N., Jiang, J. H., Fan, J., and Yung, Y. L.: Ice nucleation by aerosols from anthropogenic pollution, Nat. Geosci., 12, 602-607, 2019. 